\title{
SOBRE LA CRONOLOGÍA DEL INICIO DE LA IMPOSICIÓN CUZQUEÑA EN CHILE
}

\author{
Luis Cornejo $^{1}$
}

\begin{abstract}
Resumen
Se discute la cronología en que el norte y centro de Chile fue incorporado al Tawantinsuyu. Partiendo de la ya generalizada opinión acerca de que la fecha de 1470 DC para la incorporación de estos territorios, propuesta a partir de los estudios clásicos de Rowe no coincide con los datos arqueológicos, se analiza una extensa base de datos de fechas de $\mathrm{C}^{14}$ y termoluminiscencia, con lo cual generamos una probabilidad acumulada de la cronología inca en Chile. Nuestros resultados indican que este evento ocurrió casi 100 años antes de 1470 DC, aunque existirían diferencias entre las distintas regiones analizadas.
\end{abstract}

Palabras claves: radiocarbono - termoluminiscencia - Tawantinsuyu Chile.

Abstract

We discuss the chronology of the incorporation of North and Central Chile into Tawantinsuyu. Based on the widespread view that Rowe's $1470 \mathrm{AD}$ proposal does not match with the archaeological data, we analyze an extensive database of ${ }^{14} \mathrm{C}$ and thermoluminescence dates and generate an accumulated probability of inca's chronology in Chile.

Our results indicate that this event occurred almost 100 years before $1470 \mathrm{AD}$, although differences between regions analyzed exist.

Key words: radiocarbon - thermoluminescence - Tawantinsuyu - Chile. Recibido: agosto 2013. Aceptado: enero 2014.

\section{* Introducción}

Como bien señalara Schiappacasse (1999), el problema de la cronología del Estado inca no es un tema del todo resuelto. Estudios realizados tanto en el núcleo del Imperio (Adamska y Michczynski 1996; Bauer y Covey 2002) como en distintas provincias incas (Pärssinen y Siiriänen 1997; Williams y D'Altroy 1998; D'Altroy et al. 2000; Ogburm 2012), pese a que en general son muy localizados o considerando pequeños conjunto de muestras, han señalado que las fechas tradicionales de Rowe (1944) no son compatibles con los datos arqueológicos actuales. De esta manera, ya es claro que la propuesta de Rowe heredó, a través de los relatos indígenas que recogen los textos coloniales, una compleja mezcla de cronología, política e ideología (Zuidema 1982; Silverblatt 1988; McCormac 2001; Covey 2006).

También existe en este tema una serie de dificultades analíticas propias del acercamiento arqueológico a la cronología. Éstas se relacionan principalmente con el margen de error de los métodos arqueométricos disponibles y el corto tiempo en que ocurrieron los hechos históricos asociados a la expansión incaica. Así, cualquier fecha $\mathrm{C}^{14}$ con una $\sigma$ relativamente pequeña, por ejemplo 40 años, podría encontrarse en cualquier punto dentro de un rango de 130 años, rango que en determinados lugares podría abarcar prácticamente todo el período incaico. De hecho, es común que muestras tomadas desde sitios sin evidencias europeas, tengan fechas cuya probabilidad incluye varios años dentro del período Colonial. A esto es necesario agregar aquellas incertidumbres propias de los procesos de formación

\footnotetext{
1 Departamento de Antropología, Facultad de Ciencias Sociales, Universidad Alberto Hurtado. Almirante Barroso 10, Santiago, CHILE. Email:1cornejo@uahurtado.cl
} 
de los materiales arqueológicos datados, de los procedimientos de recuperación de estas muestras por parte de los arqueólogos, de la precisión estratigráfica o la asociación entre contexto y muestras fechadas.

Obviamente, al ser el incaico un fenómeno político expansivo de gran extensión geográfica y alto impacto para las poblaciones locales, una de las interrogantes principales es la fecha en que se produjo la incorporación de cada nuevo territorio al sistema estatal cuzqueño. Esta fecha, más que ser un dato histórico-cultural que podría ser considerado anecdótico, permite determinar el tiempo que duró la ocupación incaica de un territorio, dato central para comprender mejor cuestiones como las formas de dominación sobre las poblaciones locales, la eficiencia de sistema administrativo estatal o, incluso, la misma necesidad inca de expandirse.

En este artículo pretendemos contribuir a este problema desde el territorio chileno, tradicionalmente incluido dentro la provincia inca del Collasuyu, aportando con una base de datos actualizada de fechas, tanto de $\mathrm{C}^{14}$ como de termoluminiscencia, y con un método analítico centrado en la acumulación de probabilidades que desde dicha base de datos se puede construir.

\section{* Antecedentes, datos y método}

El territorio en el que nos centraremos, que coincide con desarrollos culturales preincaicos más o menos bien definidos, ha tenido un desarrollo de la investigación sobre lo incaico escasamente sistemático y con grandes diferencias dentro de las distintas regiones en que puede ser dividido (Uribe 1999-2000), esto es Tarapacá, Atacama, Norte Semiárido y Zona Central (Figura 1). Cabe señalar que el territorio comprendido entre Atacama y el Norte Semiárido, conocido como Despoblado de Atacama (prácticamente no habitado en tiempos prehispánicos), no se ha incluido en ninguna región ni ha sido tratado separadamente, ya que las evidencias incas ahí presentes, especialmente el camino, no son fácilmente asignables a la relación con alguna población local (Niemeyer y Rivera 1983; Lynch y Núñez 1994).

Pese a esto, Schiappacasse en su estudio pionero sobre la cronología inca, con especial referencia al territorio

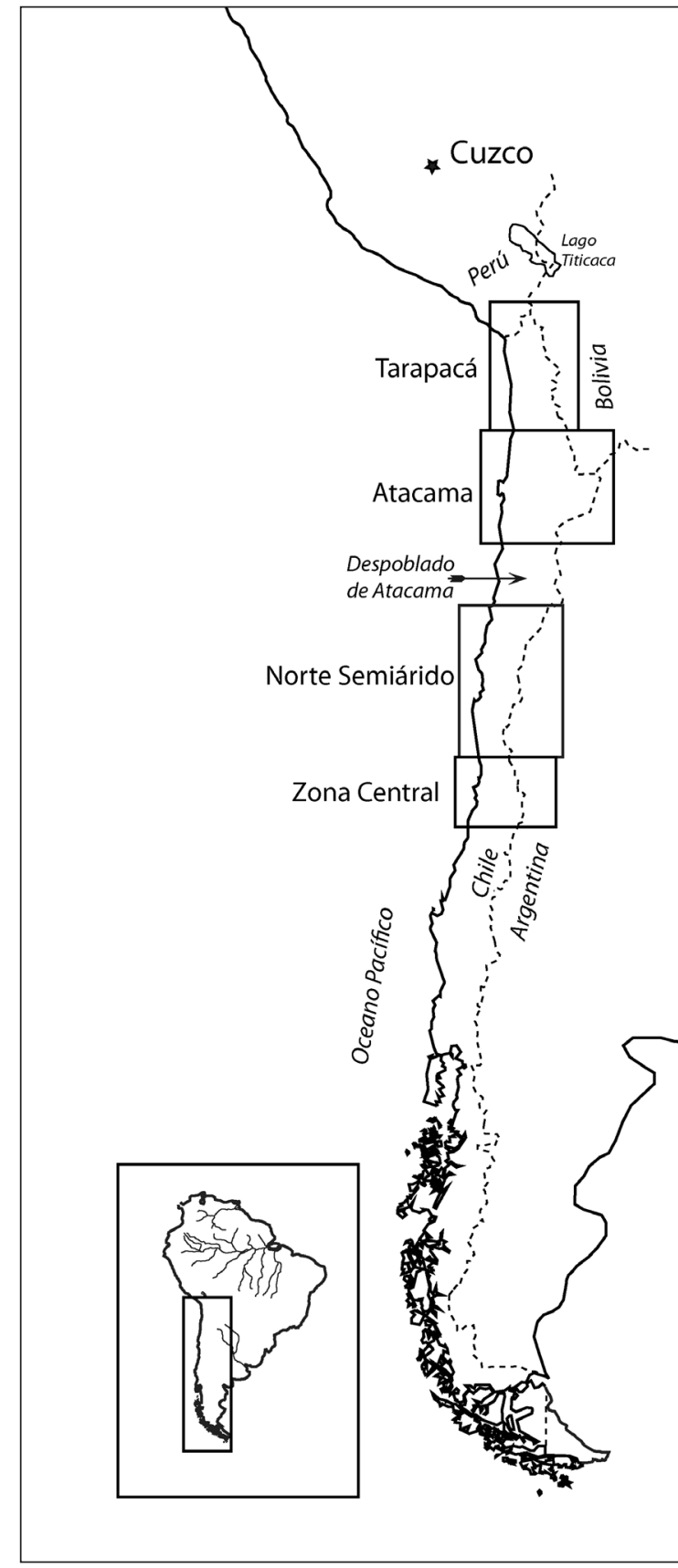

Figura 1. Mapa de las regiones consideradas en Chile.

chileno, logró reunir cerca de 70 fechas, las cuales le permitieron concluir que "[...] aceptando una corrección de 30 años a la fecha propuesta [1470 DC]" (1999: 139), no se podía despreciar el hecho que existiría una aceptable cantidad de dataciones que sugerirían una fecha anterior 
a 1400 DC. Este resultado es completamente compatible con la tesis de Stehberg (1991), quien a partir de la observación de los datos en el Norte Semiárido y en la Zona Central ha planteado que la incorporación de esta región al Tawantinsuyu sería anterior a la fecha convencionalmente aceptada.

Para profundizar esta discusión hemos reunido aquí una base de datos que incluye un universo de $214 \mathrm{fe}-$ chas, 59 de ellas sobre la base de $\mathrm{C}^{14}$ y 155 basados en termoluminiscencia, proveniente de todo el territorio central y norte de Chile, incluyendo las ya utilizadas por Schiappacasse (1999) que hemos recalibrado con el método que señalamos más adelante. La decisión de utilizar fechas obtenidas por dos métodos distintos tiene como principal limitación la diferencia matemática de cada uno de ellos, ya que el rango calendárico dentro del cual se encontraría probablemente el evento fechado con $\mathrm{C}^{14}$ depende de la desviación estándar y de la forma de la curva de calibración, mientras que en el caso de la termoluminiscencia ese rango está determinado por una proporción de error estimado (Deza y Román 1986). Esto imposibilita utilizar un método basado en probabilidad bayesiana que ha resultado muy útil en el caso de la inferencia cronológica basada en $\mathrm{C}^{14}$ (p.e., Michczynski y Pazdur 2003; Zeidler et al. 1998; Ogburn 2012), pero nos permite trabajar con una base de datos mucho más amplia. Por lo demás, como ya veremos, fechar por termoluminiscencia vasijas con estilos claramente incaicos permite contrastar los resultados, obviando en parte la incertidumbre que potencialmente tienen las fechas basadas en $\mathrm{C}^{14}$ por el posible sesgo de la madera antigua (Schiffer 1986), siempre latente en territorios áridos, como la mayor parte de las regiones aquí estudiadas.

Para comprender mejor la posible diferenciación a lo largo del territorio chileno, hemos segregado las muestras en cuatro regiones, basándonos principalmente en grandes territorios en los que se puede observar cierto grado de unidad cultural en tiempos preincas e incaicos, y donde se reconocen procesos de incorporación al Tawantinsuyu. Estas regiones son Tarapacá, Atacama, Norte Semiárido y Zona Central. Resulta evidente que existen diferencias apreciables en la cantidad de fechas basadas en $\mathrm{C}^{14}$ entre las distintas regiones, asimetría que disminuye ligera- mente al considerar las fechas basadas en termoluminiscencia, aunque es obvio que la Zona Central posee una muestra mucho menor. Esto debe tenerse en mente al considerar algunos de los resultados comparativos que aquí presentamos, aunque como puede apreciarse en la Tabla 1 el margen de error de las muestras se encuentra entre $12.5 \%$ y $15.9 \%$.

\begin{tabular}{|c|c|c|c|c|}
\hline Región & $\mathbf{C}^{14}$ & Termoluminiscencia & Total & $\begin{array}{c}\text { Margen de error } \\
\text { muestral }^{1}\end{array}$ \\
\hline Tarapacá & 18 & 38 & 46 & $14.5 \%$ \\
\hline Atacama & 29 & 34 & 62 & $12.5 \%$ \\
\hline Semiárido & 8 & 50 & 58 & $12.8 \%$ \\
\hline Central & 5 & 33 & 38 & $15.9 \%$ \\
\hline Subtotal & 59 & 155 & 214 & \\
\hline
\end{tabular}

Tabla 1. Distribución de fechas incas de Chile, por región y técnica utilizada. ${ }^{1}$ Margen de error del tamaño muestral a la probabilidad 0.05

A partir de estos datos se descompuso cada fecha en décadas dentro de las cuales el evento fechado tiene una probabilidad de encontrarse, información que se utilizó para determinar la frecuencia de probabilidad acumulada de dataciones de cada década en la escala calendárica para cada región (Tabla 2). Así, por ejemplo, la década de 1460 DC tiene una frecuencia acumulada de $101 \mathrm{da}-$ taciones que tienen una probabilidad de encontrarse en ella, sumando todas las regiones. Las ya mencionadas diferencias matemáticas y metodológicas determinaron que cada tipo de fecha fuera tratada de manera distinta. Las fechas de $\mathrm{C}^{14}$ fueron calibradas con el programa Calib 7.0 basándose en la curva $\mathrm{SHCal}_{3}$ (Hogg et al. 2013), utilizando el rango que permite un $95 \%$ de probabilidad para descomponerla en décadas, es decir $2 \sigma$. En el caso de las fechas de termoluminiscencia, el margen de error estimado por el laboratorio se utilizó con un valor de \pm 1 error estimado para cada caso.

Antes de considerar los resultados globales es necesario consignar que existen algunas discrepancias entre los resultados producidos por ambas técnicas arqueométricas de datación. Al comparar las medias de las distribuciones de frecuencias de probabilidad para cada 


\begin{tabular}{|c|c|c|c|c|}
\hline Décadas & Tarapacá & Atacama & Norte Semiárido & $\begin{array}{c}\text { Zona } \\
\text { Central } \\
\end{array}$ \\
\hline Pre 1200 & 14 & o & 65 & o \\
\hline 1200 & 3 & o & 5 & o \\
\hline 1210 & 3 & o & 7 & o \\
\hline 1220 & 3 & o & 7 & o \\
\hline 1230 & 4 & o & 9 & 1 \\
\hline 1240 & 4 & ○ & 9 & 1 \\
\hline 1250 & 4 & o & 10 & 1 \\
\hline 1260 & 4 & o & 10 & 1 \\
\hline 1270 & 7 & 1 & 10 & 1 \\
\hline 1280 & 7 & 2 & 10 & 2 \\
\hline 1290 & 6 & 2 & 10 & 2 \\
\hline 1300 & 6 & 6 & 12 & 3 \\
\hline 1310 & 7 & 7 & 11 & 3 \\
\hline 1320 & 7 & 12 & 15 & 5 \\
\hline 1330 & 7 & 12 & 17 & 6 \\
\hline 1340 & 8 & 13 & 17 & 7 \\
\hline 1350 & 8 & 13 & 19 & 8 \\
\hline 1360 & 9 & 13 & 19 & 9 \\
\hline 1370 & 9 & 12 & 19 & 11 \\
\hline 1380 & 9 & 17 & 18 & 12 \\
\hline 1390 & 15 & 18 & 19 & 13 \\
\hline 1400 & 17 & 18 & 21 & 14 \\
\hline 1410 & 20 & 20 & 21 & 14 \\
\hline 1420 & 20 & 20 & 22 & 18 \\
\hline 1430 & 23 & 21 & 20 & 21 \\
\hline 1440 & 22 & 21 & 22 & 22 \\
\hline 1450 & 24 & 25 & 23 & 25 \\
\hline 1460 & 25 & 26 & 25 & 25 \\
\hline 1470 & 25 & 21 & 23 & 27 \\
\hline 1480 & 27 & 21 & 22 & 25 \\
\hline 1490 & 26 & 19 & 20 & 27 \\
\hline 1500 & 26 & 21 & 22 & 25 \\
\hline 1510 & 22 & 21 & 21 & 21 \\
\hline 1520 & 21 & 19 & 17 & 19 \\
\hline 1530 & 23 & 22 & 16 & 15 \\
\hline 1540 & 23 & 21 & 17 & 16 \\
\hline 1550 & 25 & 25 & 15 & 11 \\
\hline 1560 & 20 & 25 & 13 & 9 \\
\hline 1570 & 17 & 25 & 11 & 9 \\
\hline 1580 & 17 & 25 & 7 & 8 \\
\hline 1590 & 16 & 22 & 7 & 8 \\
\hline 1600 & 15 & 21 & 8 & 7 \\
\hline 1610 & 13 & 23 & 6 & 7 \\
\hline 1620 & 14 & 17 & 3 & 7 \\
\hline 1630 & 11 & 15 & 2 & 2 \\
\hline 1640 & 6 & 9 & 2 & o \\
\hline 1650 & 5 & 7 & 1 & o \\
\hline Post 1650 & 3 & 41 & 7 & ○ \\
\hline
\end{tabular}

Tabla 2. Frecuencia absoluta de probabilidades acumuladas por década para las cuatro regiones estudiadas (los extremos de la tabla se presentan resumidos por problemas de espacio). método de datación en cada región, seobservan diferencias (Figura 2). Estas diferencias son difíciles de explicar, ya que hay infinidades de aspectos relativos a los procesos de formación de las muestras y de los sitios mismos, que son imposibles de evaluar con un volumen de datos obtenido de la bibliografía. Sin embargo, al analizar en detalle las diferencias es posible observar que al comparar los dos métodos en Atacama, donde hay aproximadamente la misma cantidad de fechas de cada método, y su distribución es aproximadamente normal, sus medias no son significativamente diferentes $(t=1.88 ; p=0.06)$, resultado que discrepa de lo propuesto previamente por Bárcena (1998) en su estudio sobre estas técnicas y su aplicación a la arqueología de Cuyo, Argentina. Esto nos lleva a pensar que el principal agente de este sesgo sería la diferencia en la cantidad de fechas de $\mathrm{Tl}_{\text {y }} \mathrm{C}^{14}$ disponibles (ver Tabla 1), aunque también puede estar jugando un papel la amplitud de tiempo que representa las fechas $\mathrm{C}^{14}$. Este, en promedio es casi el doble que el de las fechas $\mathrm{Tl}\left(\mathrm{Tl}=106.6\right.$ años y $\mathrm{C}^{14}=196.8$ años), con un sesgo hacia tiempos post incaicos especialmente en Tarapacá, Atacama y la Zona Central (ver Figura 2).

De esta manera, decidimos generar las distribuciones de probabilidades acumuladas para cada región con las fechas $\mathrm{Tl}$ y $\mathrm{C}^{14}$ indiferenciadamente. En estas distribuciones pondremos atención a su cola izquierda, es decir, la parte más temprana de la distribución, para intentar definir el punto en que la probabilidad acumulada cambia significativamente como para marcar el eventual inicio del dominio inca. Esta definición se tomará comparando la distribución observada con una distribución esperada construida como una progresión exponencial de incremento en la probabilidad por década, comportamiento característico del crecimiento vegetativo de un evento, y completamente distinto a lo que debiera ocurrir en el caso de una imposición de un dominio imperial expansivo que ocurre en poco tiempo. Se utilizará como elemento discriminante, es decir, para fijar el punto de quiebre de la tendencia, la distribución de probabilidades de significación estadística de la prueba KolmogórovSmirnov (K-S), un estadístico no paramétrico diseñado para comparar la bondad del ajuste de dos distribuciones, en este caso una observada y otra esperada. Éste nos permitirá definir en cual década la diferencia en ambas distribuciones alcanza el tamaño mínimo para ser significativo a la probabilidad de 0.05 (valor conocido como 


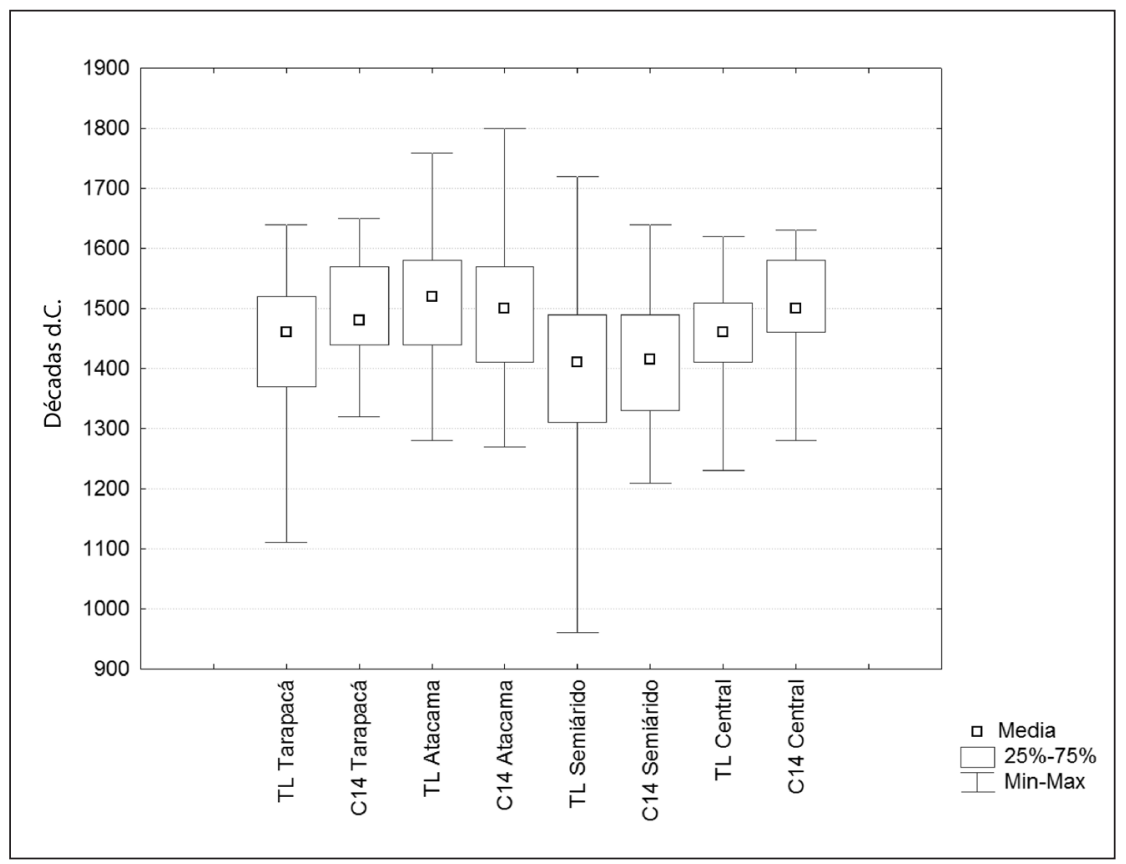

Figura 2. Gráficos de caja y arbolantes de comparación de medias de fechados sobre $\mathrm{Tl}_{\text {y }} \mathrm{C}^{14}$ por regiones.

$\mathrm{K}-\mathrm{S} \alpha$ ), generalmente aceptada para rechazar la hipótesis nula de que ambas distribuciones son iguales. Este procedimiento analítico no incluirá la parte más baja de la cola izquierda, descartando todas las probabilidades anteriores a la década de $1200 \mathrm{DC}$, momento en el que, de acuerdo a estudios como los de Adamska y Michczynski (1996) y Bauer y Covey (2002), aún no había comenzado la expansión inca, y que introducen un ruido estadístico innecesario, acumulando bajas probabilidades. ${ }^{2}$

Por último, realizaremos separadamente un análisis particular de algunas muestras de Tl. considerando que las características propias del método -la selección de fragmentos de vasijas que presenten estilos incaicos, ya sean locales o foráneos-, nos permite fechar un claro marcador de la presencia cuzqueña. Obviamente, siempre queda el posible sesgo derivado de la importación a regiones aún no sometidas al Imperio, de vasijas con estilos incaicos; sin embargo, como la mayoría de las muestras fechadas son versiones locales de decoraciones o formas incas, y las piezas eventualmente importadas son también

2 Tarapacá $=3.1 \%$; Atacama $=0 \%$; Norte Semiárido=9.8\%; Zona Centro $=0 \%$. reconocibles, este sesgo puede ser evaluado. Ya que este conjunto está representado por bastante menos fechas, utilizaremos como punto discriminante el señalado por el valor de la más alta probabilidad posible en la distribución de la prueba Kolmogórov-Smirnov. Los resultados de este análisis solo serán presentados para las regiones de Tarapacá y el Norte Semiárido, ya que en Atacama y la Zona Central no se encontraron resultados estadísticamente significativos.

\section{* Resultados}

Desde un punto de vista general y solo mirando las distribuciones de probabilidades por década (ver Tabla 2), es evidente que la fecha de 1470 DC definida para este territorio a partir del registro histórico (Rowe 1944) no se sostiene, ya que una parte muy importante de la probabilidad acumulada es anterior a ese momento en las distintas regiones aquí consideradas. ${ }^{3}$ Más aún, si se consideraran todas las fechas del territorio chileno en un conjunto (Figura 3), se

3 Tarapacá=50.3\%; Atacama =37.3\%; Norte Semiárido=66.2\%; Zona Centro $=48.1 \%$. 
120

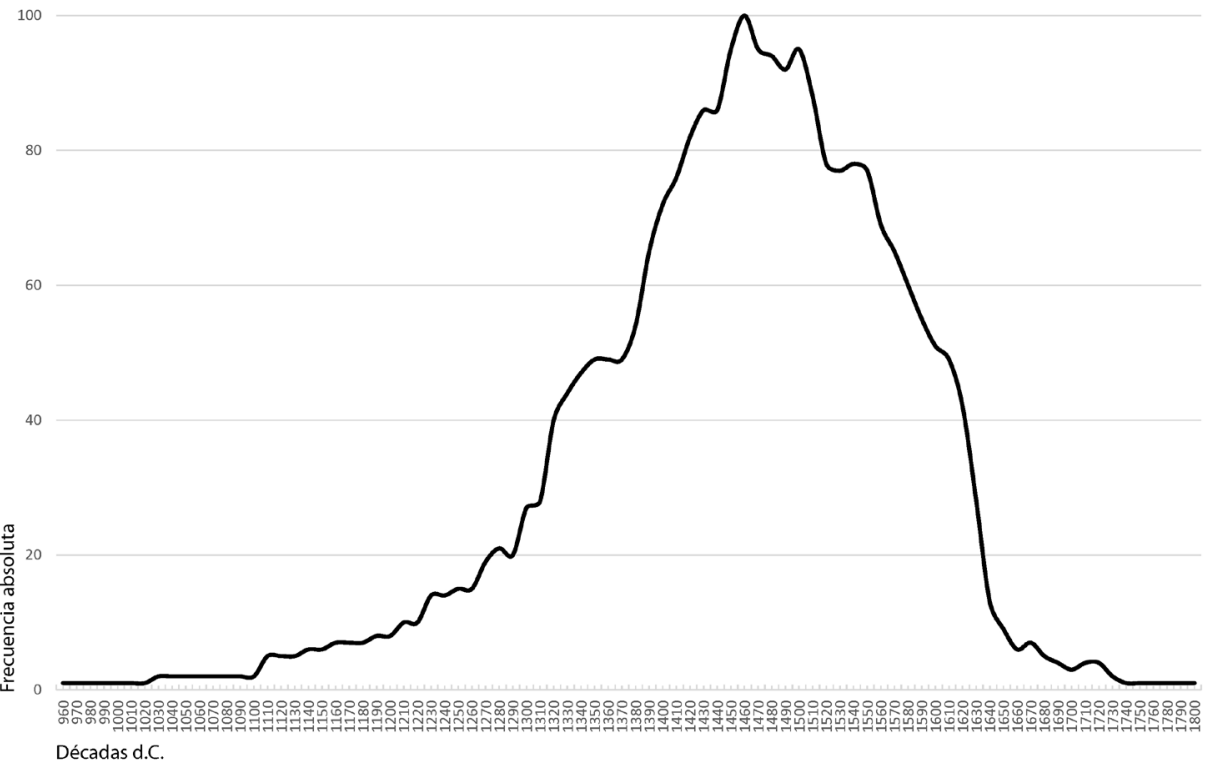

Figura 3. Curva de probabilidades acumuladas para la cronología inca en Chile.

observa que con una media de 1453 años DC $(\sigma=117.1)$ el $50.3 \%$ de la probabilidad del evento inca es anterior a 1470 DC, y que el $29.6 \%$ es anterior a 1400 DC.

\section{Tarapacá}

Los datos de esta región provienen principalmente de las tierras altas de Arica e Iquique (Tabla 3), siendo evidente su carencia en los valles bajos. Pese a que ambas se caracterizan por distintas poblaciones pre-incas, aparentemente en ambas el proceso de incorporación al Tawantinsuyu estuvo en gran medida vinculado al altiplano (Llagostera 1976; Durston e Hidalgo 1997; Uribe 1999-2000; Berenguer y Cáceres 2008). A partir de ellos se genera una distribución de probabilidades acumuladas (Figura 4) que alcanza una media correspondiente a 1463 DC $(\sigma=109.6)$, con un claro sesgo en la cola izquierda y un abrupto cambio en la tendencia de las probabilidades acumuladas alrededor de la década de 1380 y 1390 DC, y uno menor entre 1260 y 1270 DC. Esta distribución muestra que cerca del 50\% de la probabilidad es anterior 1470 DC y que el $22.1 \%$ es incluso anterior 1400 DC. No obstante esto, al comparar la distribución observada con la esperada de crecimiento exponencial, se nota que no hay una diferencia significativa entre ellas (K-S=0.090 p>0.05), lo que parecería señalar un incremento sostenido a lo largo del tiempo en la presencia de elementos incas, más que un momento específico donde esa presencia se vuelva significativamente mayor, alcanzando toda la curva la forma de una distribución normal $(W=0.963 ; p=0.0001)$.

No obstante, en el análisis de las muestras de cerámica de estilos inca de la región (Figura 5), se advierte claramente un punto de corte entre la cola izquierda de distribución de probabilidades acumuladas y la distribución exponencial esperada en la década de 1410 DC con un valor altamente significativo (K-S=0.199 p>0,o1). Sin embargo, considerando el valor de K-S $\alpha$ en la probabilidad de 0.05, también aparece como significativo el punto casi un siglo anterior, localizado en 1320 DC. Este último punto, contemporáneo con el eventual inicio de la fase Inca Expansiva (Adamska y Michczynski 1996; Bauer y 


\begin{tabular}{|l|l|}
\hline \multicolumn{1}{|c|}{ Región } & \multicolumn{1}{c|}{ Sitios } \\
\hline Tarapacá & $\begin{array}{l}\text { El Tojo-Collacagua, Husaco 1 (Berenguer y Cáceres 2008); Mamilla 7 (Salazar et al. 2010); Pubriza, Zapahuira 1 y 2, Huaycuta, Laco Alto, } \\
\text { Huaihuarane, Incahullo, Trigalpampa, Ancopachane, Saxamar, Cobija 1, Incauta, Molle Grande 1, Monita, Tambo Chungara, Tambo Tacora, } \\
\text { Tambo Caquena, Tambo 1, Caleta Camarones Norte, Hacienda Camarones, Pachica, Saguara y Saguara 2 (Schiappacasse 1999; Schiappacasse } \\
\text { y Niemeyer 2002), TR4011, TR4010, TR4005 y TR400o (Zori y Tropper 2010). }\end{array}$ \\
\hline Atacama & $\begin{array}{l}\text { CG-9, DE-1, LR-1, MI-2, NA-7, SBA-162, SBA-518 (J. Berenguer, com. pers. 2010); Incahuasi Inca (Adán 1999; Adán y Uribe 2005); Pukara } \\
\text { de Turi (Aldunate 1993); Pukara de Turi, CW, Tramo CN, CE, Col, TZ (Proyecto QhapaqNan CMN 2012). }\end{array}$ \\
\hline Norte Semiárido & $\begin{array}{l}\text { Iglesia Colorada, La Aduana, La Puerta, Tambo El Castaño (Niemeyer et al. 1996), Tambo Pasteadero, Tambo Laguna Chica, Tambo Colinai } \\
\text { (Schiappacasse 1999); Céspedes 3, Familia Carvajal, Huintil 6, La Colonia 8, Parcela Gerardo Toro, Pisco Control (Rodríguez et al. 2004), } \\
\text { Estadio Fiscal de Ovalle (Cantarutti y Mera 2004); Punta Alcalde (Endesa 2009). Fundo Coquimbo (Schiappacasse 1999); El Castaño (Gaete } \\
\text { 1999); Conchuca, La Laguna Guandacol, Laguna Chica, Colinai (Stehberg 1995), Ranquil 5, LV og9b (Pavlovic et al. 2010). }\end{array}$ \\
\hline Zona Central & $\begin{array}{l}\text { El Castillo, El Tartaro (Sánchez et al. 2004); Metro Quinta Normal (Reyes et al. 2005); Cerro La Cruz (Schiappacasse 1999), Cerro Grande de } \\
\text { la Compañía (Planella y Stehberg 1994); Santa Rosa (Stehberg y Sotomayor 1999); Cerro Tren Tren (Stehberg 1989); Chada (Planella y Steh- } \\
\text { berg 1997); Cerro Mercachas (Sánchez 2004); Rengo (Cáceres et al. 1993); Mauco, Estación Quillota (Venegas et al. 2011) y Palacio de la Real } \\
\text { Aduana (actualmente en estudio por nosotros). }\end{array}$ \\
\hline
\end{tabular}

Tabla 3. Sitios de cada región desde los cuales provienen los datos aquí utilizados.

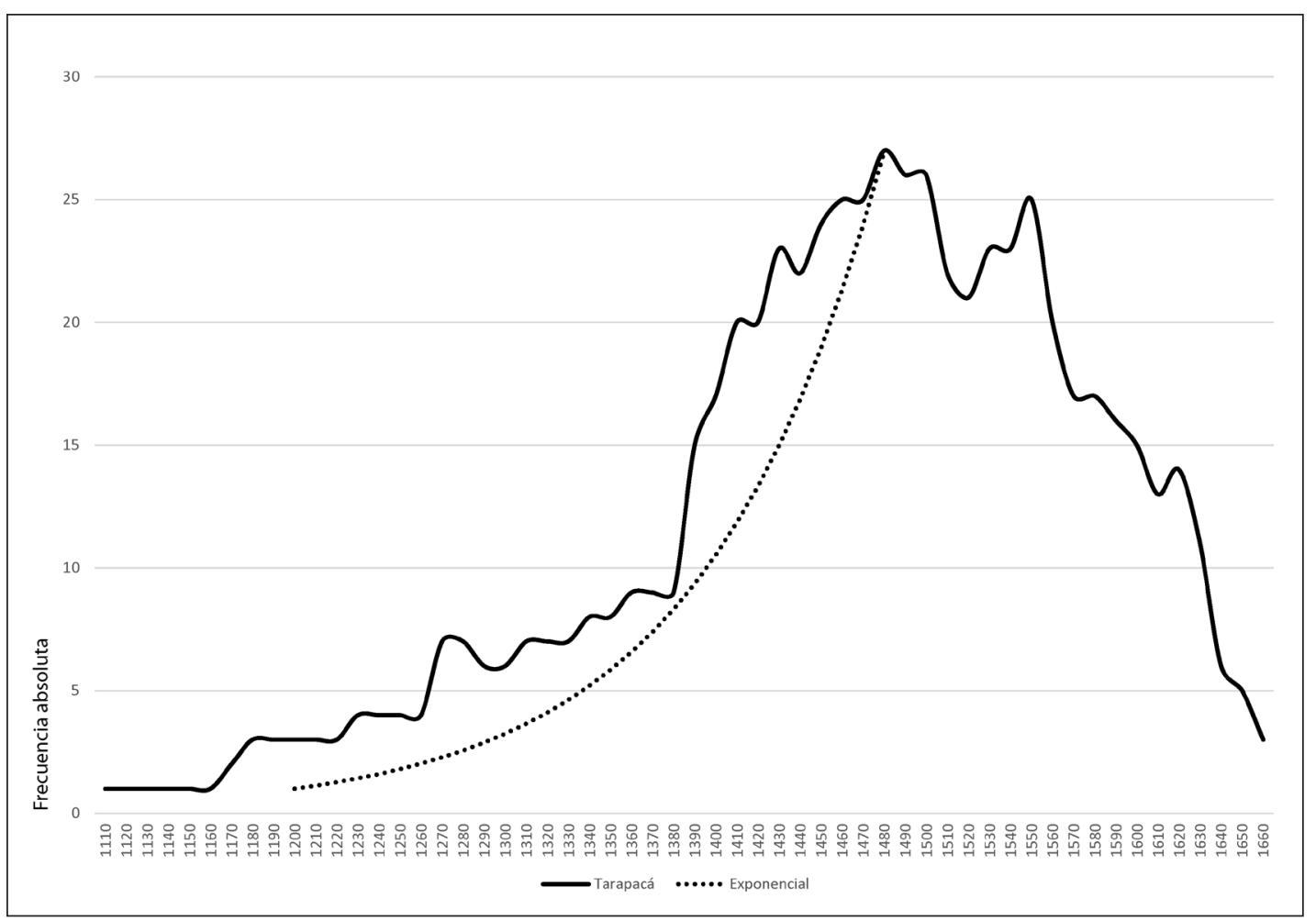

Figura 4. Curva de probabilidades acumuladas para la cronología inca en Tarapacá comparada con curva exponencial teórica.

Covey 2002), creemos que se puede explicar por la presencia de algunas muestras clasificadas como "Inka Altiplánico" e "Inka Cuzqueño" en la base de datos tomada de Schiappacasse (1999). Estas podrían haber llegado a la región incluso antes de la expansión inca desde su centro, ubicado a poco más de $600 \mathrm{~km}$ de distancia, o también desde el altiplano cercano previamente a que comenzara la expansión inca propiamente tal, como se ha 


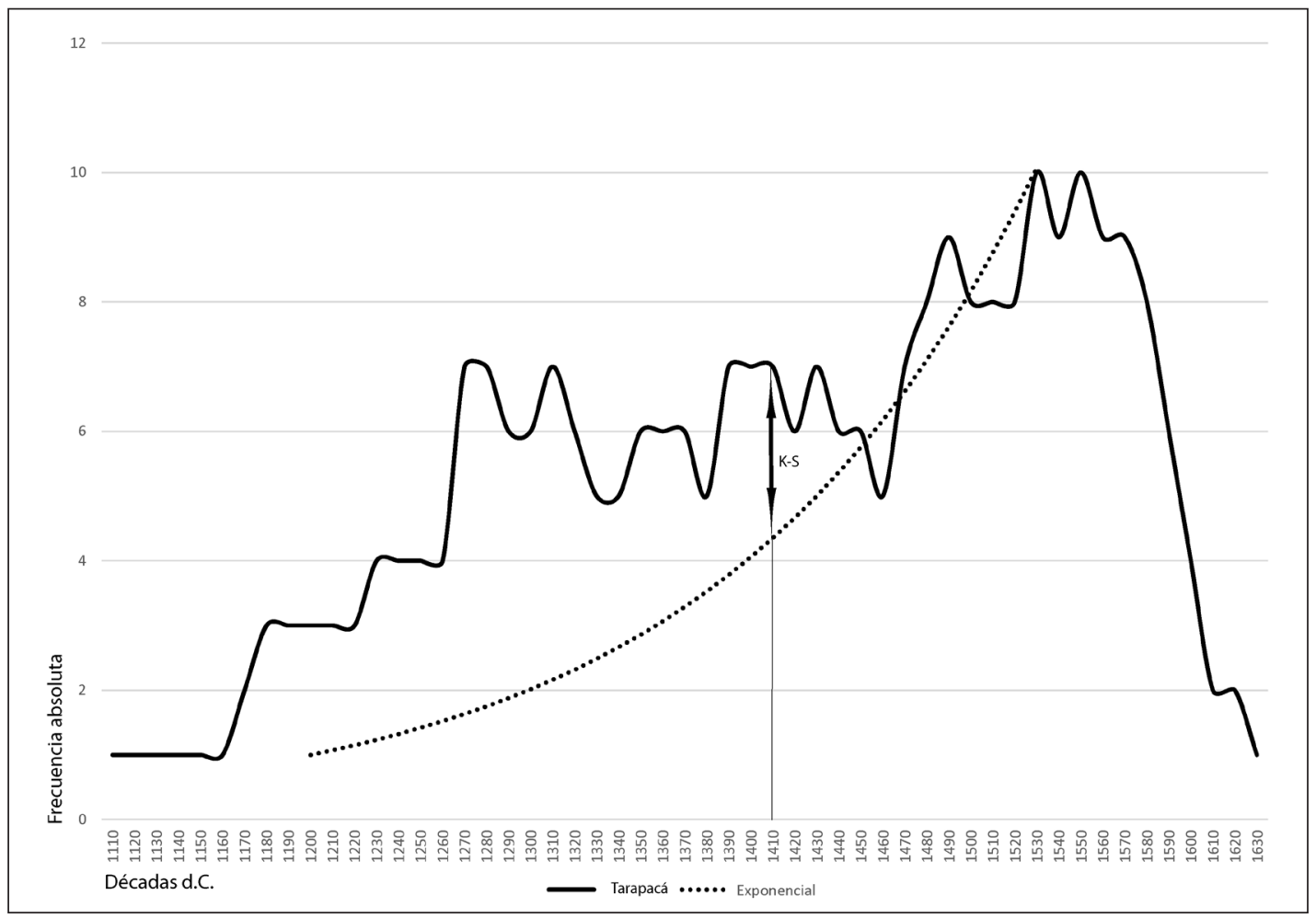

Figura 5. Curva de probabilidades acumuladas para la cronología Tl de cerámica de estilo inca en Tarapacá comparada con curva exponencial teórica.

propuesto a partir de estudios alfareros en dicha región (Pärssinen y Siiriänen 1997; Pärssinen 2005).

Observando ambos datos y manteniendo las reservas antes señaladas, creemos posible que la presencia inca en esta región, como dijimos la más cercana al núcleo inca, ocurrió dentro de un proceso en el cual la llegada de elementos antes del dominio efectivo de esta región por parte de los incas comenzara en un punto cercano a 1380 años DC, donde la distribución de probabilidades de todo el conjunto tiene un importante, aunque no significativo cambio de tendencia, mientras que 1410 años DC, tal como propone la distribución de probabilidades acumuladas para la cerámica, podría ser el punto de inicio del dominio efectivo de la región.

\section{Atacama}

Los datos de esta región provienen de las tierras altas del río Loa y del salar de Atacama (ver Tabla 3). Ambas se caracterizan por un panorama pre-inca que incluye a comunidades con diferentes matices, pero parte de una tradición común, la que ha sido llamada Tradición del Desierto (Castro et al. 1984). Aquí el dominio inca se caracteriza por una marcada presencia de centros donde se edifica arquitectura inca como parte de una agenda de dominación (Gallardo et al. 1995), especialmente asociados a la minería (Llagostera 1976; Cornejo 1995; Uribe 1999-2000; Salazar et al. 2013), pero donde, a diferencia de muchas otras regiones conquistadas por el Inka, la incorporación de elementos iconográficos incaicos en la alfarería local sea casi nula (Uribe 2004).

La distribución de probabilidades, con una media de 1498 DC $(\sigma=103.28)$ presenta un aspecto muy curioso, con una forma bimodal (Figura 6). Esta deja el $42.8 \%$ de la probabilidad antes de 1470 DC y solo el $18.2 \%$ anterior a 1400 DC. Esta forma bimodal que, de hecho podría ser calificada más propiamente como multimodal, nos obliga a analizar su correspondencia con dos 


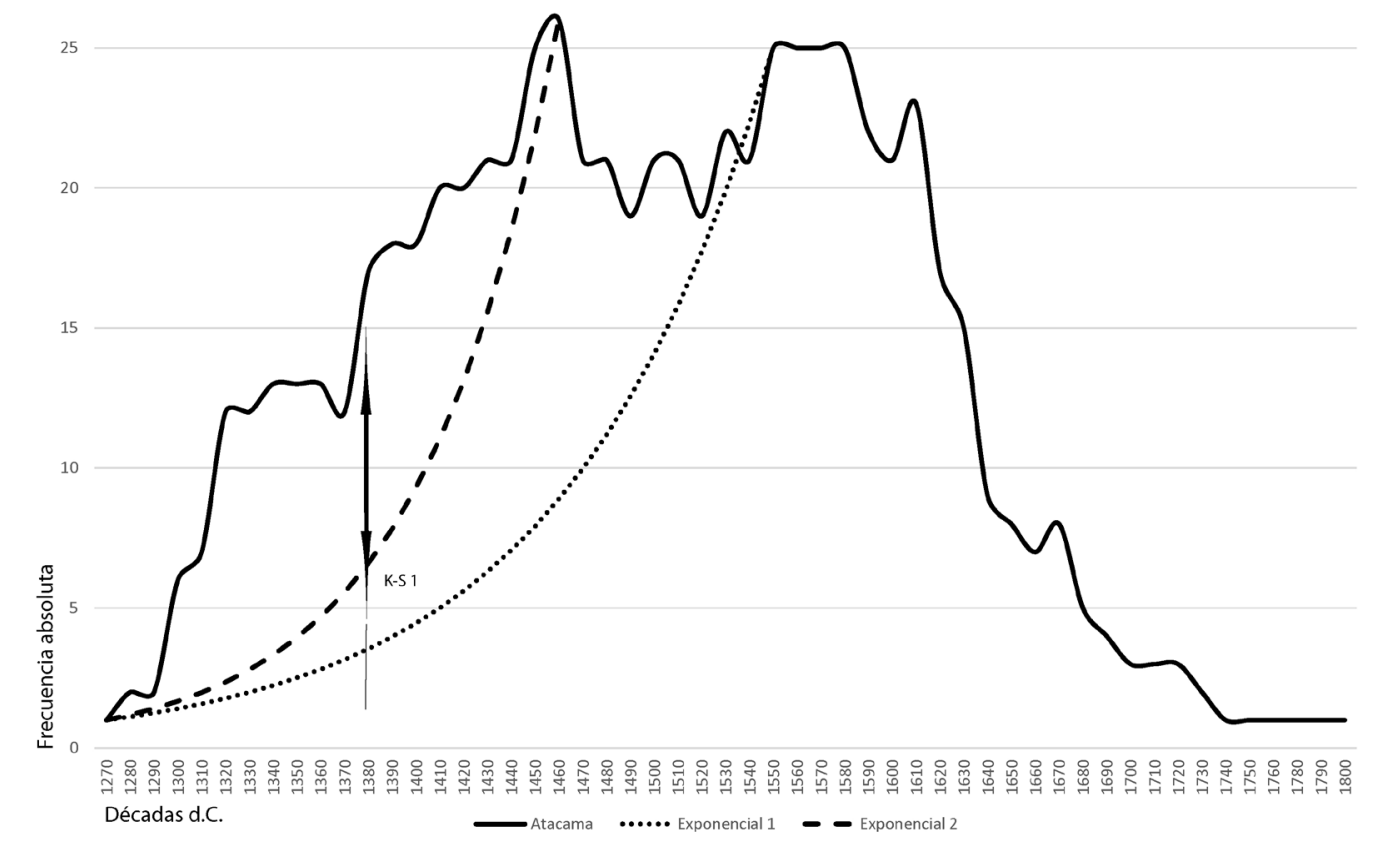

Figura 6. Curva de probabilidades acumuladas para la cronología inca en Atacama comparada con curva exponencial teórica.

curvas esperadas de crecimiento exponencial, una para la moda mayor (1460 DC) y otra para la segunda moda (entre 1550 y 1580 DC). En este caso, en la medida que no hay probabilidades anteriores a $1270 \mathrm{DC}$, esta fecha será el inicio de las proyecciones exponenciales utilizadas como contraste.

En el primer caso no se aprecia un valor de discrepancia significativo entre lo observado y la distribución exponencial (K-S=0.100 p>0.05), mientras que en el segundo caso sí se apreciaría un punto de corte significativo que se ubicaría en 1380 DC (K-S=0.124 p>0.05). Esta diferencia, así como todo el comportamiento de la distribución de probabilidades acumuladas, resulta difícil de explicar, aunque creemos que es posible interpretarla a la luz de lo que previamente se ha planteado para la dominación inca en Atacama. Una distribución de más de una moda a lo largo de una serie temporal, usualmente significa que el evento estudiado tiene pulsos distintos a lo largo del tiempo, lo cual podría corresponderse con la hipótesis planteada por Llagostera (1976) sobre las dos fases de la dominación inca en los Andes Meridionales, una indirecta y una directa, y que nosotros hemos refrendado en nuestro estudio de la arquitectura del Pukara de Turi, en la cuenca del río Loa (Cornejo 1999). Es este marco, la primera moda podría corresponder al momento del inicio del dominio indirecto, lo que se verificaría como un aumento exponencial de las evidencias incaicas y sin un punto de corte evidente, mientras que la segunda parte de distribución sí presenta un punto de corte, 1380 DC, que podría señalar del inicio del dominio directo. Cabe señalar, que esta hipótesis sobre dos fases de ocupación inca, está en cierto sentido, como señala Uribe (19992000), fuertemente influenciada por la percepción de los tipos cerámicos como marcadores étnicos, aunque como agrega el mismo autor, ella no ha sido discutida realmente en el contexto de una interpretación global de la forma del dominio inca en estas regiones.

De manera complementaria, la presencia de una alta frecuencia en las probabilidades que definen la primera moda, podría también ser un efecto de la llegada de 
elementos incaicos a Atacama por medio de redes de intercambio, sin necesariamente estar involucrado algún grado de vinculación política entre ambas regiones, situación similar a la ya descrita para Tarapacá.

\section{Norte Semiárido}

Los datos de esta región provienen de un amplio territorio que va desde el valle de Copiapó hasta el río Choa$\mathrm{pa}$, concentrados especialmente en las tierras altas (ver Tabla 3). Este territorio incluye a dos tradiciones culturales pre-inca, Copiapó y Diaguita, que si bien están plenamente diferenciadas al inicio de la dominación inca, parecen tener elementos comunes en su origen (Niemeyer et al. 1996). Aquí la conquista inca parece tener un proceso en el cual primero es dominada la población diaguita, y luego ésta participa en la anexión del territorio Copiapó (Castillo 1997; Cornejo 2001a).

La curva de distribución de las probabilidades acumuladas formada por estos datos tiene un sesgo hacia la cola izquierda (Figura 7), aunque menos pronunciada que la de la curva de Tarapacá (ver Figura 4). Esta distribución tendría la media más baja de todas las regiones (1394 DC), y daría pie a que el $66.2 \%$ de la probabilidad sea anterior a 1470 DC y un $44.6 \%$, es decir, casi la mitad de la probabilidad, sería anterior a 1400 DC. Presenta sin embargo, la mayor dispersión $(\sigma=136.1)$ de todas las regiones, lo que señalaría la menor heterogeneidad del conjunto datado.

Al comparar la distribución observada de probabilidades acumuladas con la esperada exponencial, se puede observar que el punto de corte de la prueba K-S (K-S=0.116 p>0.05) se encontraría en la década de $1300 \mathrm{DC}$, lo que resulta sorprendentemente temprano considerando que sería coincidente con el período en que recién estaría comenzando el fenómeno expansivo inca (Adamska y Michczynski 1996; Bauer y Covey 2002). Creemos que esto se podría explicar por la forma que tiene la cola izquierda, ya que si se analiza su distribución comparada con una progresión exponencial cuyo principio coincida con el inicio de la distribución de probabilidades acumuladas (960 DC), resulta que ambas no son estadísticamente distintas, con un valor máximo de diferencia (K-S=0.053 p<0.05), lo que dificulta la discriminación clara de un punto de quiebre.
En consecuencia, nos parece recomendable acoger como punto de quiebre en la dirección de la tendencia, el punto con el valor K-S para la probabilidad más alta (0.218 p>0.001), el que se encontraría en la década de 1370 DC, que proponemos tentativamente como el inicio del dominio inca en esta región.

Como apoyo a esta propuesta, el análisis de las fechas $\mathrm{Tl}$ hechas sobre fragmentos asignados a tipos incas, entrega la misma fecha de 1370 DC como punto de discriminación para la comparación entre las distribuciones observada en la cola izquierda y esperada exponencial (Figura 8), el que resulta altamente significativo (K-S $=0.248$ p>o.001). Adicionalmente, dada la marcada diferencia entre estas dos distribuciones, existe un punto anterior que también resulta significativo, esta vez a la p>0.05, el que se ubica también en un punto muy temprano de la secuencia, 1290 DC, repitiéndose así, una situación muy similar a lo que constatamos previamente al considerar todas la fechas del Norte Semiárido.

Como posible interpretación a este punto tan temprano, creemos que puede haber un grado de error en la identificación de las tipologías incas de los fragmentos fechados, dado que el desarrollo diaguita anterior al inca en esta región fue muy profuso en la producción de vasijas pintadas con motivos geométricos tricromos, relativamente similares a los que después forman parte de iconografía tanto inca cuzqueña como inca local (Cornejo 2001a; González 2013). Sin duda, resolver las deficiencias que generan la baja cantidad de fechas para los valles de Elqui y Limarí, territorio nuclear de los diaguitas, que jugaron un papel central en el dominio inca, tanto en el Norte Semiárido como en la Zona Central (Cornejo 2001b; Stehberg y Sotomayor 2012), permitirá un mejor posicionamiento cronológico de este evento.

\section{Zona Central}

La Zona Central es la frontera sur del Tawantinsuyu, y está representada por un territorio mucho menor que los anteriores, que se extiende entre los valles del río Aconcagua y la parte norte de la cuenca de Rancagua, proviniendo en general las muestras aquí incluidas de los valles interiores (ver Tabla 3). En esta región la presencia inca también está asociada a la presencia diaguita, que parece deberse 


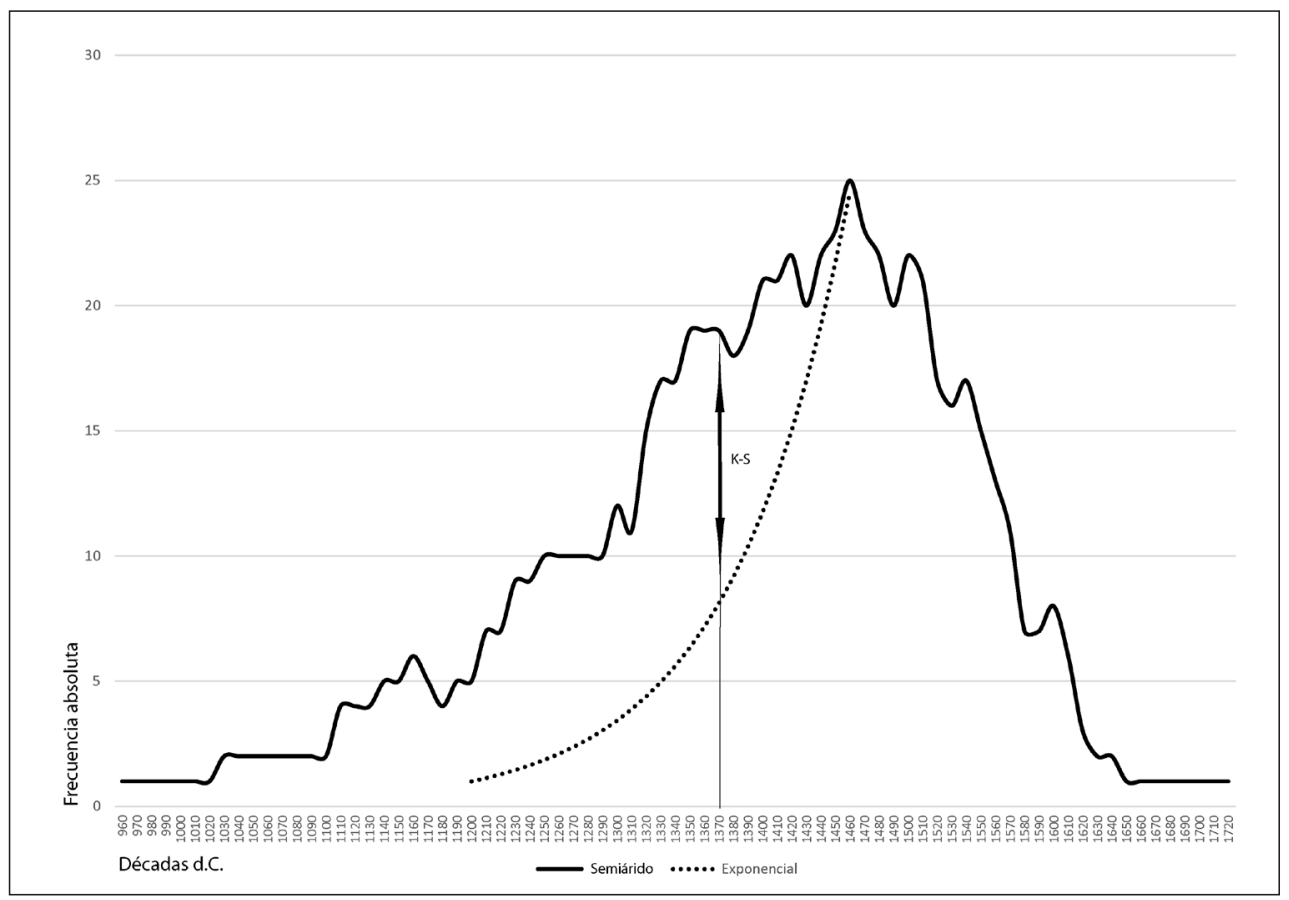

Figura 7. Curva de probabilidades acumuladas para la cronología inca en el Norte Semiárido comparada con dos curvas exponenciales teóricas.

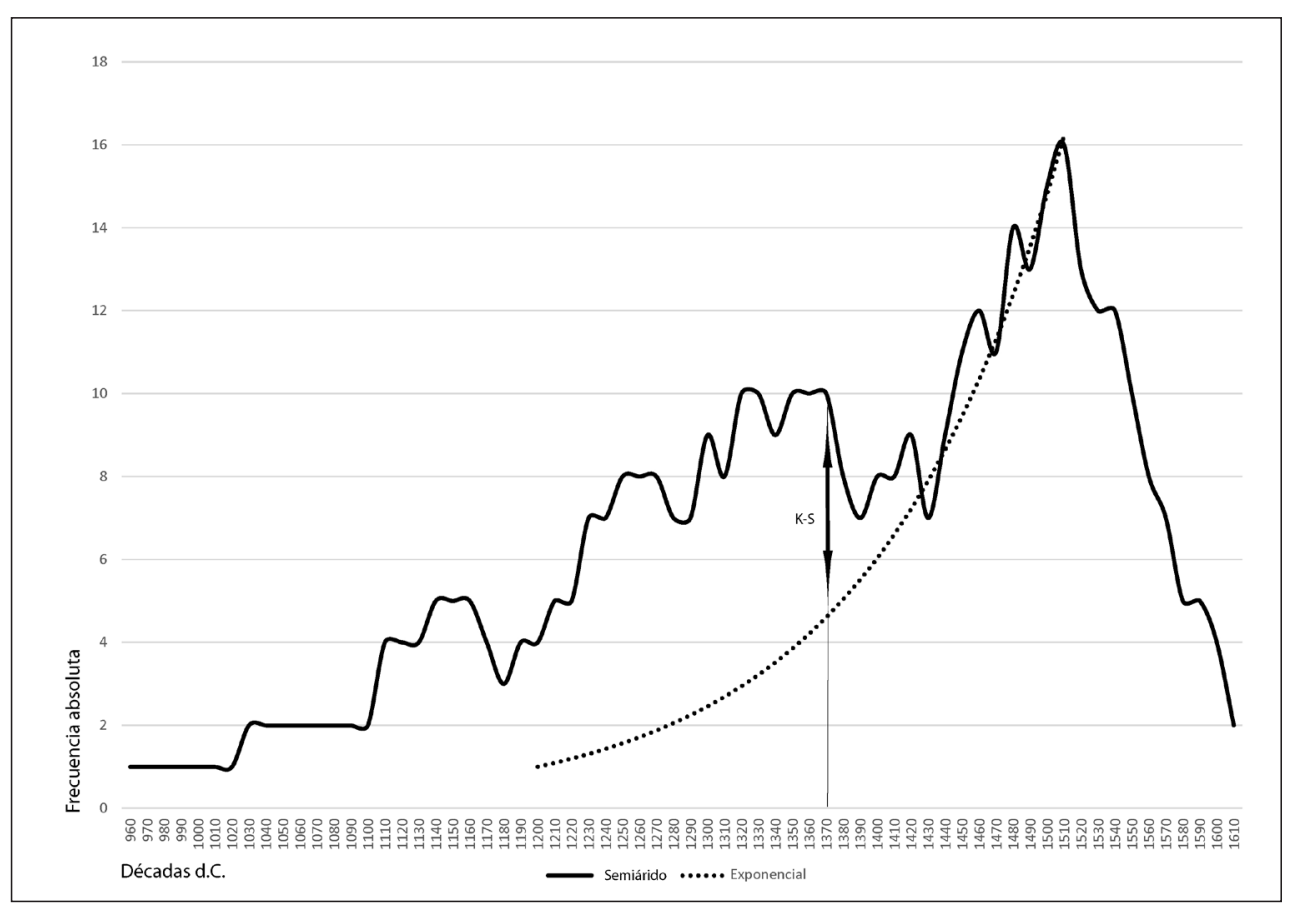

Figura 8. Curva de probabilidades acumuladas para la cronología Tl de cerámica de estilo inca en el Norte Semiárido comparada con curva exponencial teórica. 
a los mitimaes implementados por el Imperio (Cornejo 20o1b; Stehberg y Sotomayor 2012).

Los datos de esta región producen una distribución de probabilidades acumuladas significativamente normal (Shapiro-Wilk $W=0.99123 ; p=.00715$ ) con una media de 1464 DC $(\sigma=77.18)$, la cual produce que el $48.1 \%$ de la probabilidad se encuentre antes de 1470 DC, y un $21.3 \%$ antes de 1400 DC (Figura 9). A partir de la forma de esta distribución se podría estimar con un 95\% de probabilidad $(2 \sigma)$ que la fase Inca en esta región tiene un margen de tiempo entre 1310 y 1619 años DC. Este resultado podría ser la respuesta a la pregunta que aquí nos planteamos, fijando el punto en 1310 DC. No obstante, esta fecha tan temprana, incluso anterior a la del Norte Semiárido, parece poco probable considerando que esas poblaciones tuvieron un rol protagónico en la ocupación inca de la Zona Central (Cornejo 2001a).

Por otro lado, el método que hemos utilizado en las otras regiones para definir un punto de corte entre la distribución observada y la esperada, que en este caso tendría su base en 1270 DC, no presenta resultados esclarecedores. Como era de esperar por la forma aproximadamente normal de la distribución, la diferencia con la proyección exponencial no es muy grande, y no fue posible encontrar ningún valor que alcanzara a ser significativo (K-S=0.035 pro.05). Evidentemente, este resultado no es satisfactorio considerando el supuesto básico inicial de nuestro análisis, ya que la conducta de los datos señala un aumento progresivo de la presencia inca, más que una imposición que ocurre en un tiempo relativamente rápido.

En esta etapa del análisis surgen dos alternativas que se deberán contrastar en el futuro, al disponer de más fechados. Por un lado, es probable que simplemente el tamaño de la muestra, el más pequeño disponible para todas las regiones aquí estudiado, con un margen de error muestreal de $15.9 \%$, genere una distribución que no sea suficientemente sensible para detectar el inicio del evento inca. Este pequeño tamaño de la muestra, de hecho, podría ser la razón por la cual la distribución de las probabilidades acumuladas genere una curva normal, modelo que se asocia a muestras generadas al azar y no producto de un patrón. Por otro lado, es también posible que las ya conocidas vinculaciones entre la parte alta del valle del Aconcagua y el territorio diaguita durante el período anterior (Sánchez el at. 2004), haya posibilitado la llegada de alfarería diaguita inca a la Zona Central antes de la anexión de este territorio al Tawantinsuyu, generándose así una imagen de la presencia inca que va creciendo de manera exponencial a lo largo del tiempo.

Sin embargo, en este caso en particular creemos que se puede explorar otra posibilidad para determinar el inicio de la imposición inca, aprovechando la simetría entre las dos colas que caracterizan a las distribuciones normales como la aquí estudiada, es decir, el momento del inicio de la imposición inca y el final de ella. Esta simetría estadística nos parece que debería tener ciertas coincidencias con los procesos políticos implicados en el inicio y final de la era inca en Chile Central, ya que ambos ocurren por la imposición de un poder estatal foráneo que cambia las reglas políticas, económicas y sociales.

A partir de esta simetría, podríamos estimar que el error en la determinación del rango de tiempo de la imposición inca en la Zona Central en un extremo de la distribución temporal debiera ser relativamente similar al del otro extremo y, afortunadamente, tenemos bases para estimar el error en el extremo tardío de la secuencia. Si bien sabemos que el proceso de colapso del Imperio comienza en 1532 DC en su territorio nuclear, es evidente que los cambios posibles de detectar por medio de las técnicas arqueométricas de datación (uso de sitios incas, producción de alfarería inca local, entre otros) no se verificarán en la Zona Central hasta después de 1541 DC, cuando Pedro de Valdivia se instala definitivamente en el valle del Mapocho. Entonces podemos utilizar esta fecha para estimar un margen de error en las dataciones en la cola derecha de nuestra distribución de probabilidades acumuladas.

Así, si el límite al 95\% de confiabilidad en la cola derecha es 1619 DC, podemos definir que tendría al menos un margen de error de 78 años al compararlo con la ya señalada fecha de instalación del dominio español en este territorio, que dada la escala de décadas que hemos utilizado, podríamos fijar en 80 años. Seguidamente podríamos asumir, que ese mismo margen de error sería posible aplicarlo al inicio de la secuencia, que como dijimos, debiera ser simétrico con el final, estimando que si la distribución normal nos propone un límite inferior con un 95\% de probabilidad en 1310 DC, al considerar el 


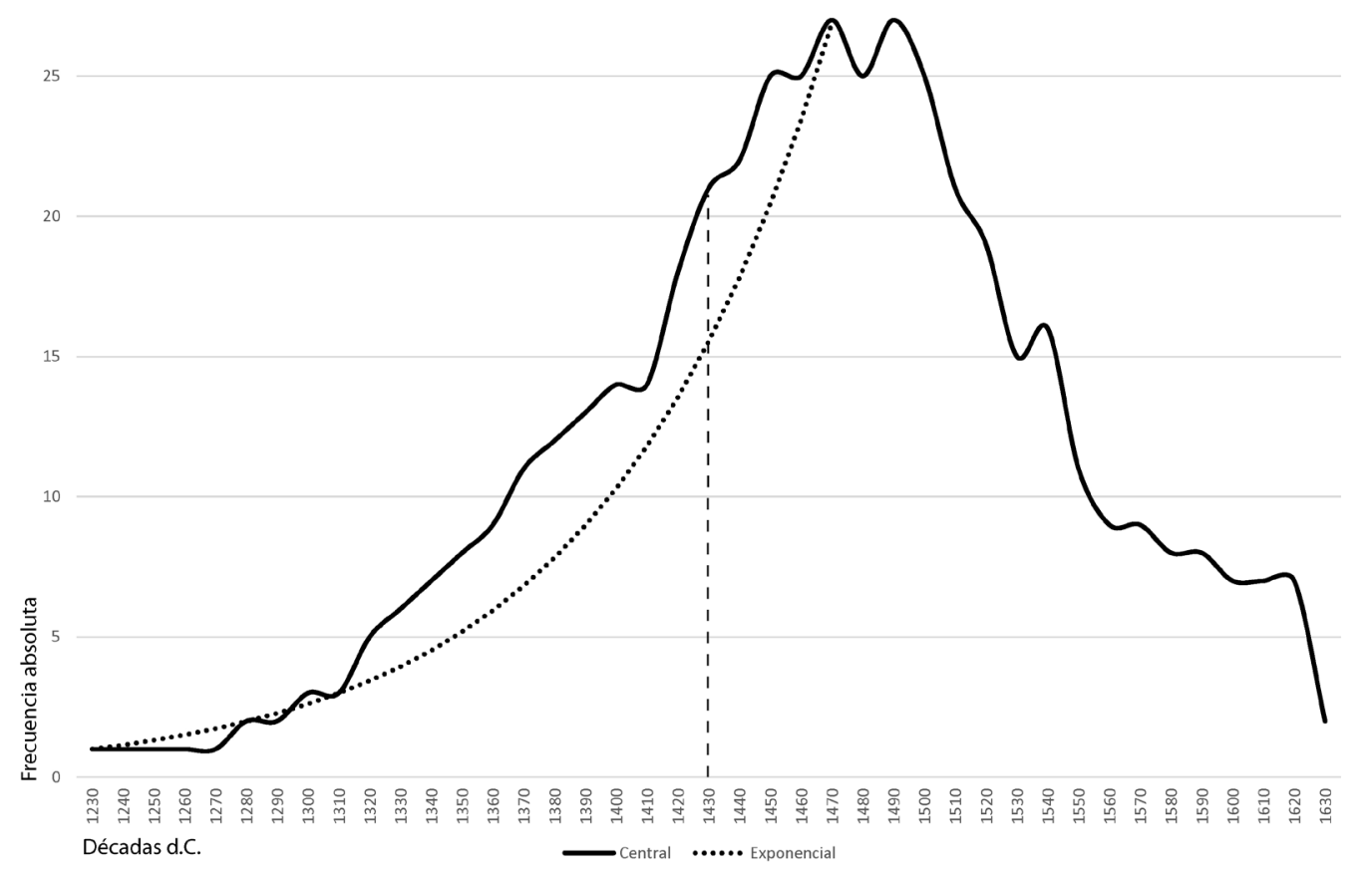

Figura 9. Curva de probabilidades acumuladas para la cronología inca en la Zona Central comparada con curva exponencial teórica.

margen de error, la fecha tentativa del inicio de la imposición inca en la Zona Central se podría fijar en 1390 DC. Este último valor podría ser entonces provisionalmente considerado como un posible inicio para la imposición inca en la frontera sur del Tawantinsuyu.

\section{* Conclusiones}

La metodología aquí aplicada nos ha permitido formular hipótesis sobre el momento en que eventualmente habría comenzado la imposición incaica para la mayor parte del territorio chileno alguna vez anexado al Tawantinsuyu, definido en escala de décadas. Para Tarapacá proponemos que eso habría ocurrido en la década de 1410 DC, mientras que en Atacama se podrían identificar las dos fases sucesivas, la primera sin un punto de inflexión claro, y la segunda que comenzaría en 1380 DC, lo que sería coincidente con la proposición de dos etapas en la imposición inca en esta región (Llagostera 1976; Cornejo 1999). En el Norte Semiárido, por su parte, el evento podría desa- rrollarse a partir de $1370 \mathrm{DC}$, mientras que en el caso de la Zona Central sería posible ubicarla unos 20 años después, en 1390 DC.

Así, resulta evidente que la imposición inca en esta parte de Collasuyu habría ocurrido hasta un siglo antes de lo que tradicionalmente se pensaba a partir de la propuesta de Rowe (1944). Esto, obviamente, permite dar un mejor contexto a las profundas trasformaciones que se observan en los territorios anexados al Imperio. De hecho, sí trasformamos la escala cronológica aquí utilizada a generaciones (asumiendo una generación cada 25 años) se concluye que, por ejemplo, la imposición inca en el Norte Semiárido, que comenzaría en la década de 1370 DC, afectó al menos a seis generaciones de diaguitas. Visto de esta manera, es posible entender procesos como la profunda trasformación de la alfarería diaguita o el papel que este grupo habría tenido en la expansión inca en el Norte Semiárido y en la Zona Central, otorgándole una escala de trasformación cultural muy distinta a la concebible a partir de la fecha tradicional. 
A la vez, es posible observar que dentro del territorio estudiado hay diferencias relativamente importantes, especialmente entre Tarapacá y el resto de las regiones analizadas. Mientras en las regiones más alejadas del Cuzco, Atacama y el Norte Semiárido se presentan fechas entre 1370 y 1390 DC, en Tarapacá los resultados serían unas tres décadas posteriores, pese a su mayor cercanía al Cuzco. Esta situación, que obviamente debe ser considerada como una hipótesis, nos propone mirar la expansión inca hacia el Collasuyu de una manera más compleja que el avance norte-sur que se podría suponer en función de la simple contingencia espacial. En dicho contexto es posible que la ya referida tesis de Llagostera (1976), que si bien como señala Uribe (2004) está cargada de una analogía directa entre cerámica y etnicidad, nos muestra una posible vía interpretativa.

En esta mirada, la idea de que durante un tiempo el dominio inca en los Andes Meridionales era mediatizado por grupos étnicos altiplánicos y que tendrían antiguos intereses en la región, podría explicar por qué las fechas de contextos incas en Tarapacá tendrían fechas con un pulso inicial en fechas posteriores a otras regiones, más alejadas de la esfera altiplánica. Una interpretación como ésta, aunque basándose en distintas evidencias, ha sido recientemente ofrecida por Berenguer y Cáceres (2008) para el sur del altiplano de Tarapacá, destacándose la diferencia en relación a la arquitectura inca, emblemática de dicha región, con la subregión más septentrional de Atacama, el Alto Loa.

Estas interpretaciones y cualquiera otra que pudiera derivarse de estas conclusiones cronológicas, deben considerarse como hipótesis que deben seguir siendo testeadas, para lo que es importante mejorar el tamaño de la muestra. Esto es especialmente cierto si se tiene en consideración, además, que las fechas aquí incluidas están distribuidas de manera caprichosa a lo largo y ancho del territorio estudiado, subsistiendo grandes regiones donde casi no tenemos información cronológica de las evidencias incaicas (p.e., interfluvio Elqui-Limarí o costa de Arica). Más aún, dadas las condiciones económicas en que se desarrollan la mayor parte de las investigaciones arqueológicas, muchos de los sitios incas más relevantes están ubicados en el tiempo solo por medio de uno o dos fechados arqueométricos.

Para terminar, es necesario señalar que algunas de las decisiones que hemos tomado en este análisis se basan en los resultados de los estudios cronológicos referentes al área nuclear incaica. Esto es especialmente importante cuando hemos considerado en el Norte Semiárido y la Zona Central que los primeros resultados de nuestro análisis deben ser incorrectos por ser "muy tempranos", en relación a lo que sabemos acerca del inicio del proceso expansivo desde Cuzco.

Sin embargo, este supuesto tiene el evidente sesgo de que dichos estudios en el área nuclear han trabajado con una cantidad muy pequeña de muestras, estando distante una hipótesis sólida sobre el momento en que los incas pasan de ser un Estado regional a un Estado imperial. Así, los resultados aquí propuestos, sin duda debieran invitar a investigar con mayor detalle la cronología del desarrollo del Tawantinsuyu como el Estado dominante del panorama cultural de los Andes y más allá.

Agradecimientos Comprometen nuestro agradecimiento José Berenguer, Miguel Cervellino y el proyecto QhapaqNanan del Consejo de Monumentos Nacionales (CMN), quienes pusieron a disposición nuestra los datos de que disponían. Lorena Sanhueza realizó una lectura crítica del manuscrito y los comentarios de los evaluadores permitieron mejorarlo significativamente.
ADÁN, L., 1999. Aquellos antiguos edificios. Acercamiento arqueológico a la arquitectura prehispánica tardía de Caspana. Estudios Atacameños 18: 13-34.

ADÁN, L. y M. URIBE, 2005. El dominio inca en la localidad de Caspana: Un acercamiento al pensamiento político andino (río Loa, norte de Chile). Estudios Atacameños 29: 41-66.
ADAMSKA, A. y A. MICHCZYNSKI, 1996. Towards radiocarbon chronology of the Inca State. Boletín de la Misión Arqueológica Andina 1: $35-58$

ALDUNATE, C., 1993. Arqueología del Pukara de Turi. Actas del XII Congreso Nacional de Arqueología Chilena, vol. 2, pp. 61-78. Sociedad Chilena de Arqueología, DIBAM, Temuco. 
BÁRCENA, R., 1998. Arqueología de Mendoza. Las dataciones absolutas y sus alcances. Editorial de la Universidad Nacional de Cuyo, Mendoza.

BAUER, B. y A. COVEY, 2002. Processes of State formation in the Inca heartland (Cuzco, Peru). American Anthropologist 104 (3): 846-864.

BERENGUER, J. e I. CÁCERES, 2008. Los inkas en el altiplano sur de Tarapacá: El Tojo revisitado. Chungara, Revista de Antropología Chilena 40 (2): 121-143.

CÁCERES, I., E. ASPILLAGA, A. DEZA y A. ROMÁN, 1993. Un sitio agroalfarero tardío en la cuenca del río Cachapoal. Actas del XII Congreso Nacional de Arqueología, vol. 1, pp. 423-428. Sociedad Chilena de Arqueología, DIBAM, Temuco.

CASTILLO, G., 1997 Los períodos Intermedio Tardío y Tardío: Desde la Cultura Copiapó al dominio inca. En Culturas prehistóricas de Copiapó, H. Niemeyer y M. Cervellino (Eds.), pp. 163282. Museo Regional de Atacama, Copiapó.

CASTRO, V., C. ALDUNATE y J. BERENGUER, 1984. Orígenes altiplánicos de la fase Toconce. Estudios Atacameños 7: 209-235.

CANTARUTTI, G.y R. MERA, 2004. Estadio Fiscal de Ovalle: Redescubrimiento de un sitio diaguita-inca en el valle del Limarí. Chungara, Revista de Antropología Chilena, vol. especial (2): 833-845.

CORNEJO, L., 1995. El Inka en la región del río Loa: Lo local y lo foráneo. Hombre y Desierto o (1): 203-213.

1999. Los incas y la construcción del espacio en Turi. Estudios Atacameños 18: 165-176.

2001a. Los inka y sus aliados diaguita en el extremo austral del Tawantinsuyo. En Tras la huella del Inka en Chile, C. Aldunate y L. Cornejo (Eds.), pp. 74-103. Museo Chileno de Arte Precolombino, Santiago.

20o1b. Alfarería y política. En Tras la huella del Inka en Chile, C. Aldunate y L. Cornejo (Eds.), pp. 114-121. Museo Chileno de Arte Precolombino, Santiago.

COVEY, A., 2006. Chronology, succession and sovereignty: The politics of Inka historiography and its modern interpretation. Comparative Studies in Society and History 48 (1): 169-199.

D'ALTROY, T., A. LORANDI, V. WILLIAMS, M. CALDERARI, C. HASTORF, E. DEMARRAIS y M. HAGSTRUM, 200o. Inka rule in the Northern Calchaquí Valley, Argentina. Journal of Field Archaeology 27 (1): 1-26.

DEZA, A. y A. ROMÁN, 1986. La dosimetría termolumniscente en arqueología. Chungara 16-17: 403-407.

DURSTON, A. y J. HIDALGO, 1997. La presencia andina en los valles de Arica, siglos XVI-XVIII: Casos de regeneración colonial de estructuras archipielágicas. Chungara 29: 249-273.
ENDESA, 2009. Línea de base patrimonio cultural para EIA proyecto central termoeléctrica Punta Alcalde, comuna Huasco, provincia de Huasco, III región Atacama. https://www.e-seia.cl/ archivos/20090226.133014.pdf

GAETE, N., 1999. Evidencias de dominio incaico en la región de Atacama: Hacia una sistematización de la ocupación de la cuenca del río Jorquera. Estudios Atacameños 18: 223-236.

GALLARDO, F., M. URIBE y P. AYALA, 1995. Arquitectura inka y poder en el Pukara de Turi. Gaceta Arqueológica Andina 24 (7): 151-172.

GONZÁlEZ, P., 2013. Arte y Cultura Diaguita chilena. Simetría, simbolismo e identidad. Serie Monográfica 2, Sociedad Chilena de Arqueología, Santiago.

HOGG, A., H. QUAN, P. BLACKWELL, N. MU NIU, C. BUCK, T GUILDERSON, T. HEATON, J. PALMER, P. REIMER, R. REIMER, C. TURNEY y S. ZIMMERMAN, 2013. Shcali3 southern hemisphere calibration, 0-50.000 years cal. BP. Radiocarbon 55 (4): 1889-1903.

LLAGOSTERA, A., 1976. Hipótesis sobre la expansión incaica en la vertiente occidental de los Andes Meridionales. Homenaje al Dr. Gustavo Le Paige, J. M. Cassasas (Ed.), pp. 203-218. Universidad del Norte, Antofagasta.

MCCORMAC, S., 2001. History, historical record and ceremonial action: Incas and Spaniards in Cuzco. Comparative Studies in Society and History 43 (2):329-363.

MCCORMAC, F., A. HOGG, P. BLACKWELL, C. BUCK, T. HIGHAM y P. REIMER, 2004. SHCalo4 Southern Hemisphere Calibration o-11.o cal kyr BP. Radiocarbon 46 (3): 1087-1092.

MICHCZYNSKI, A. y A. PAZDUR, 2003. The method of combining radiocarbon dates and other information on application to study the chronologies of archaeological sites. Geochronometria 22: 41-46.

NIEMEYER, H. y M. RIVERA, 1983. El Camino del Inka en el Despoblado de Atacama. Boletín de Prehistoria de Chile 10: 91-193.

NIEMEYER, H., M. CERVELLINO y G. CASTILLO, 1996. Las culturas prehistóricas de Copiapó. Gobierno Regional de Copiapó, Copiapó.

LYNCH, T. y L. NÚÑEZ, 1994. Nuevas evidencias incaicas entre Collahuasi y Río Frio (I y II regiones del norte de Chile). Estudios Atacameños 11: 145-164.

OGBURN, D., 2012. Reconceiving the chronology of Inca Imperial expanssion. Radiocarbon 54 (2): 219-237.

PÄRSSINEN. M., 2005. Caquiaviri y la Provincia de Pacasa. Desde el Alto Formativo hasta la conquista española (1-1533). Colección Maestría en Historias Andinas y Amazónicas, La Paz. 
PÄRSSINEN, M. y A. SIIRIÄNEN, 1997. Inca-style ceramics and their chronological relationship to the Inca expanssion in the Southern Lake Titicaca Area (Bolivia). Latin American Antiquity 8 (3): 255-272.

PAVLOVIC, D., A. TRONCOSO, C. BECKER, J. RODRÍGUEZ y P. GONZÁLEZ, 2010. Escobillados, cuarto estilo y grandes contenedores. El conjunto alfarero inca en la provincia del Choapa.Actas de XVII Congreso Nacional de Arqueología Chilena, vol. 2, pp. 285-296. Sociedad Chilena de Arqueología, Universidad Austral, Valdivia.

PLANELLA, M. T. y R. STEHBERG, 1994. Etnohistoria y arqueología en el estudio de la fortaleza indígena de Cerro Grande de la Compañía. Chungara 26 (1): 65-78.

1997. Intervención inka en un territorio de la cultura local Aconcagua de la zona Centro-Sur de Chile. Tawantinsuyu 3: 58-78.

REYES, V., M. HENRÍQUEZ y J. SANHUEZA, 2005. Cementerio incaico Estación Quinta Normal, Línea 5 del Metro de Santiago. Actas del XVI Congreso Nacional de Arqueología Chilena, vol. 1, pp. 655-664. Sociedad Chilena de Arqueología, DIBAM, Concepción.

RODRÍGUEZ, J., 2006. La Cultura Diaguita en la frontera meridional. Actas del XVI Congreso Nacional de Arqueología, vol. 1, pp. 139146. Sociedad Chilena de Arqueología, DIBAM, Concepción.

RODRÍGUEZ, J., C. BECKER, P. GONZÁlEZ, A. TRONCOSO y D. PAVLOVIC, 2004. La Cultura Diaguita en el valle del río Illapel. Chungara, Revista de Antropología Chilena vol. especial (2): 739-751.

ROWE, J., 1944. An introduction to the archaeology of Cuzco. Papers of the Peabody Museum of American Archaeology and Ethnology 22 (2). Harvard University, Cambridge.

SÁNCHEZ, R., D. PAVLOVIC, P. GONZÁLEZ y A. TRONCO$\mathrm{SO}, 2004$. Curso superior del río Aconcagua. Un área de interdigitación cultural durante los períodos Intermedio Tardío y Tardío. Chungara, Revista de Antropología Chilena vol. especial (2): 753-766.

SALAZAR, D., C. PALMA, H. SALINAS, F. FUENTES, J. L. GUENDON y C. CASTELLÓN, 2010. Reconstrucción de la secuencia ocupacional de la quebrada de Mamilla, costa de Tocopilla, norte de Chile. Werkén 13:323-346.

SALAZAR, D., J. BERENGUER y G. VEGA, 2013. Paisajes minerometalúrgicos incaicos en Atacama y el altiplano sur de Tarapacá (norte de Chile). Chungara, Revista de Antropología Chilena 45 (1): 83-103.

SCHIAPPACASSE, V., 1999. Cronología del Estado inca. Estudios Atacameños 18: 133-140.
SCHIAPPACASSE, V. y H. NIEMEYER, 2002. Ceremonial inca provincial: El asentamiento de Saguara (cuenca de Camarones). Chungara, Revista de Antropología Chilena 34 (1): 53-84.

SCHIFFER, M., 1986. Radiocarbon dating and the "old wood" problem: The case of the Hohokam chronology. Journal of Archaeological Science 13 (1): 13-30.

SILVERBLATT, I., 1988. Imperial dilemmas, the politics of kinship, and Inca reconstructions of History. Comparative Studies in Society and History 30 (1): 83-102.

STEHBERG, R., 1991. El límite inferior cronológico de la expansión incaica en Chile. Xama 4-5: 63-89.

1995. Instalaciones incaicas en el Norte y Centro Semiárido de Chile. Centro Barros Arana, DIBAM, Santiago.

STEHBERG, R. y A. RODRÍGUEZ, 1989. Ofertorio mapucheincaico en el cerro Tren Tren de Doñihue. Revista Museos 6: 8-11.

STEHBERG, R. y G. SOTOMAYOR, 1999. Cabis, guacas-fortalezas y el control incaico del valle de Aconcagua. Estudios Atacameños 18: 237-248.

2012. Mapocho incaico. Boletín del Museo Nacional de Historia Natural 61: 85-149.

URIBE, M., 1999-2000. La arqueología Inka en Chile. Revista Chilena de Antropología 15: 63-97.

2004. El inka y el poder como problemas de la arqueología del Norte Grande de Chile. Chungara, Revista de Antropología Chilena $36(2): 313-324$.

VENEGAS, F., H. ÁVALOS y A. SAUNIER, 2011. Arqueología e historia del curso medio e inferior del río Aconcagua. Desde los primeros alfareros hasta el arribo de los españoles (300AC-1600 DC). Ediciones Universitarias de Valparaíso, Valparaíso.

WILLIAMS, V. y T. D'ALTROY, 1998. El sur del Tawantinsuyu: Un dominio selectivamente intensivo. Tawantinsuyu 5: 170-178.

ZEIDLER, J., C. BUCK y C. LITTON, 1998. Integration of archaeological phase information and radiocarbon results from the Jama river, Ecuador: A Bayesian approach. Latin American Antiquity 9 (2): 160-179.

ZORI, C. y P. TROPPER, 2010. Late pre-hispanic and early colonial silver production in the quebrada de Tarapacá, northern Chile. Boletín del Museo Chileno de Arte Precolombino 15 (2): 65-87.

ZUidemA, T., 1982. Myth and history in ancient Peru. En The logic of culture, I. Rossi (Ed.), pp. 150-175. Bergin and Garvey Publishers Inc., South Hadley, Massachusetts. 